\title{
Anesthetic Management in A Thrombocytopenic Patient with Multiple Pregnancy
}

\author{
Duygu Demiröz Aslan* and Tuğba Karartı Günal \\ Department of Anesthesiology and Reanimation,Istanbul Educational Research Hospital, Turkey \\ *Corresponding author: DuyguDemiröz Aslan, Department of Anesthesiology and ReanimationIstanbul Educational Research Hospital, Org. \\ Abdurrahman NafizGürman Cad. Etyemez, Samatya, 34098, Istanbul, Turkey
}

Submission: June08, 2018; Published: 䐷 July 10, 2018

Abstract
Thrombocytopenia is seen by $6-10 \%$ during pregnancy, with vast majority being mild dilutional thrombocytopenia occurring due to gestational

Abstract
Thrombocytopenia is seen by $6-10 \%$ during pregnancy, with vast majority being mild dilutional thrombocytopenia occurring due to gestational physiology, and $2 \%$ of thrombocytopenia are seen in preeclampsia and HELLP syndrome. Herein, we aimed to emphasized that early diagnosis is important and anesthetic approach is guiding in prevention of the possible complications in the mother and infant, in a case with normal follow-up in which we observed that isolated mild thrombocytopenia was the early and unique symptom of HELLP syndrome in multiple pregnancy.
\end{abstract}

Keywords: Thrombocytopenia;Hellpsyndrome; Cesarean section

\section{Introduction}

Thrombocytopenia is the most commonly encountered hematologic complication following anemia during gestation, and is observed in $6-10 \%$ of pregnants [1]. A platelet count between $100.000-150.000 / \mathrm{mm} 3$ is defined as mild, between $50.000-100.000 / \mathrm{mm} 3$ as moderate, and $<50.000 \mathrm{~mm} 3$ as severe thrombocytopenia. Thrombocytopenia is gestational by $75 \%$ and may resulted from gestational diseases such as dilutional, preeclampsia, eclampsia, and HELLP. Thrombocytopenia may also be due to viral infections, autoimmune diseases, thrombotic microangiopathies, disseminated intravascular coagulation (DIC), bone marrow diseases, medications, hypersplenism, and may also be hereditary. Dilutional thrombocytopenia occurs in the last trimester of pregnancy, and returns to normal with in postnatal three months [1].

Cases of preeclampsia and HELLP syndrome account for nearly $2 \%$ of thrombocytopenias observed during gestation [1]. Preeclampsia is a clinical picture which arises after 20th week of the gestation, clinically present with the triad of hypertension, proteinuria, and edema, and affects various organs and systems. Eclampsia picture manifests with addition of convulsions to preeclampsia. Coagulation system is impaired in preeclamptic patients, and platelet count is decreased because of the disruptions in prostaglandin balance or hemorrhage time may be prolonged due to platelet dysfunction despite normal platelet count in 10$15 \%$ of patients. HELLP (Hemolysis, Elevated Liver enzymes, Low Platelet count syndrome) is characterized by increased platelet aggregation, thrombocytopenia, microangiopathic hemolytic anemia, and increased liver enzymes [2,3].

\section{Case Report}

A 29-year-old patient $(73 \mathrm{~kg}$ ) in 34 th gestational week of dichorionic diamniotic twin pregnancy, who had no comorbidity except gestational diabetes mellitus and was regularly followedup, was evaluated in the outpatient clinic for preoperative cesarean section preparation. Hemogram of the patient showed HGB:14.1g/ dL, HCT:41.7\% Bk:8.100/uL, and PLT:110.000/mm3. Biochemical values included AST:26U/L, ALT:18U/L , LDH:197, coagulation values INR: 0.9 and the other parameters were normal. Considering the patient had dilutional thrombocytopenia, she was offered reevaluation of the investigations on the day of cesarean planning, and after the consent she was taken to the emergency operation after two days due to cervical dilatation, cervical shortening, and fetal stress. Investigations on the day of the operation showed HGB:12.3, HCT:36.3 PLT:57000mm3, AST:113 U/L, ALT:90U/L, LDH:433, and albumin:2.86, and coagulation parameters were between the normal values. Urine analysis revealed microalbumin: $40.6 \mathrm{mg} /$ day, and protein $370.62 \mathrm{mg} /$ day. The patient which was urgently decided to undergo cesarean section was taken to the operation under general anesthesia. Initial arterial blood pressure was $128 / 75 \mathrm{mmHg}$, and no hypertension was observed during the operation. The living twins were delivered. The operation lasted 45 minutes, the amount of hemorrhage was recorded as $580 \mathrm{~mL}$, and no additional complication was seen. The patient was extubated and taken to the intensive care postoperation. During postoperative follow-up of the patient in the intensive care unit, blood pressure, respiratory rate and heart rate were stable. Postoperative supportive treatment was planned. Because postoperative 1st day 
controls showed improvement as HGB:8.1g/dL, HCT:22.9\% and Bk:17.100/L, and vital signs were stable, 2nd day investigations were carried out and the patient was transferred to the gynecology service from the intensive care unit. Patients with 6 th day values of HGB:10.4g/dL, HCT:29.9\% Bk:9.48/uL, and PLT:323000/mm3 and biochemical parameters of AST:47U/L ALT:111U/L, and LDH:270 was discharged to home.

\section{Discussion}

Thrombocytopenia is observed by $6-10 \%$ during pregnancy, and the case of preeclampsia and HELLP syndrome account for $2 \%$ of thrombocytopenia [1]. Many risk factors are involved in preeclampsia and HELLP syndrome that may develop in pregnancy, and multiple pregnancy is among these factors [4].

The use of regional and general anesthesia methods in cesarean cases in preeclampsia and HELLP syndrome is controversial, and it is thought that blood pressure control and infant APGAR scores are better after regional anesthesia (spinal/epidural) [5,6]. Sudden and excessive decrease in blood pressure in patients to undergo general and regional anesthesia should not be allowed, negatively affected hepatic and uterine blood flow with hypotension should be taken into account, preparation should be done for difficult intubation due to edema in the airway if general anesthesia will be performed, and it should be kept in mind that sudden rising may be seen in blood pressure in response to laryngoscopy and intubation $[7,8]$.

One of the most important criteria in decision for spinal or epidural anesthesia is platelet count, and there is a risk for subdural hematoma in case of a platelet count under $100.000 / 99.000 \mathrm{~mm} 3$ [9]. Early diagnosis and effective treatment are important in HELLP syndrome, and the definitive treatment is delivery [10]. The method of choice for delivery should be cesarean. After the removal of placenta, symptoms tend to regress, and patients are seen to generally recover after 48 hours [10]. Goal of the treatment is prevention of the complications that may develop in the mother such as intracerebral hemorrhage, acute tubular and cortical necrosis, retina detachment, subcapsular hematoma and rupture in the liver, pulmonary edema, cardiac failure, disseminated intravascular coagulopathy, sepsis, and stroke [10]. HELLP syndrome also brings risk for the fetus and the week of delivery is crucial. In the case of the delivery in early gestational weeks, neonatal intensive care conditions are quite important in terms of fetal morbidity and mortality. Preterm delivery rate is about $70 \%$, and $15 \%$ of this rate belongs to gestations under 28 weeks. In conclusion, these newborns have high rate of acute neonatal complications $[11,12]$.
In our case, we encounter with mild thrombocytopenia as the unique finding in the pregnant with regular controls and investigations, and considered dilutional thrombocytopenia. Given the rapid impairment in clinical and laboratory values of our patient within 2 days, we aimed to underline importance of early diagnosis and to emphasize that the controls should be done more frequently if there is thrombocytopenia in the last trimester in multiple pregnancies in order to avoid complications of HELLP syndrome and accordingly to determine anesthetic method.

\section{References}

1. Mc Crae KR (2010) Thrombocytopenia in pregnancy. Hematology Am Soc Hematol Educ Program 2010(1): 397-402.

2. Mokriski BK, Malinow AM (1992) Preeclampsia and eclampsia: Anesthetic management. Chapter 13, ASA, USA, 20: 143-154.

3. Martin JN, Blake PG, Lowry SI, Perry KG, Files JC, et al. ( 1990) JC: Pregnancy complicated by preeclampsia-eclampsia with the syndrome of hemolysis, elevated liver enzymes, and low platelet count: How rapid is postpartum recovery? Obstet Gyne col 76: 737-741.

4. Fisher KA (1981) Hypertension in pregnancy: Clinical-pathological correlations and remoteprognosis. Medicine 60(4): 267-276.

5. Miyamoto N, Kawamata M, Okanuma M, Kawana S, Namiki (2002) Obstetrical anesthesia for parturient patients with HELLP syndrome. Masui $51(9)$ : 968-972.

6. O'Brien JM, Shumate SA, Satchwell SL (2002) Maternal benefit of corticosteroid therapy in patients with HELLP (hemolysis, elevated liver enzymes, and low platelet count) syndrome: Impact on the rate of regional anesthesia. Am J Obstet Gynecol 186(3): 475-479.

7. Santos A (1999) Spinal anesthesia in severely pre eclamptic women: When is it safe? Anesthesiology 90: 1252-1254

8. Wallace DH, Leveno KJ, Cunningham FG (1995) Randomized comparison of general and regional anesthesia for cesarean delivery in pregnancies complicated by severe pre eclampsia. Obstet Gynecol 86(2) : 193-199.

9. Ezri T, Abouleish E, Lee C, Evron S (2002) Intracranial subdural hematoma following dural puncture in a parturient with HELLP syndrome. Can J Anaesth 49(8) : 820-823.

10. Sibai BM, Ramadan MK, Usta I, Salama M, Mercer BM, et al. (1993) Maternal morbidity and mortality in 442 pregnancies with hemolysis, elevated liver enzymes, and low platelets (HELLP syndrome). Am J Obstet Gynecol 169(4) : 1000-1006.

11. Haram K, Svendsen E, Abildgaard U (2009) The HELLP syndrome: Clinical issues and management. BMC Pregnancy and Childbirth 9: 8-23.

12. Abramovici D, Friedman SA, Mercer BM, Audibert F, Kao L, et al. (1999) Neonatal outcome in severe preeclampsia at 24 to 36 weeks' gestation. Does HELLP (hemolysis, elavated liver enzymes and low platelet count) syndrom matter? Am J Obstet Gynecol 180(1): 221-225.

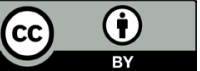

Creative Commons Attribution 4.0 nternational License

For possible submissions Click Here

\section{Submit Article}

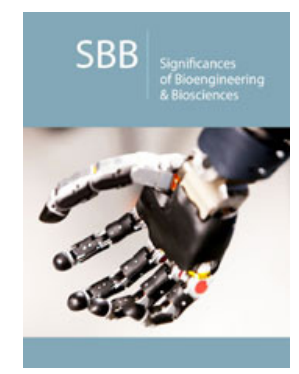

Significances of Bioengineering \& Biosciences

Benefits of Publishing with us

- High-level peer review and editorial services

- Freely accessible online immediately upon publication

- Authors retain the copyright to their work

- Licensing it under a Creative Commons license

- Visibility through different online platforms 